general insanitary and unwholesome conditions. Such measures have comprised the provision of more air, more light, greater cleanliness, better houses, cheaper food, and a better appreciation of the laws making for our general well-being.

Do not, therefore, let us accept without further examina. tion, and in face of some of the facts herein set fortb, the view that the reduction of the disease has been the result in the main of the discovery of the tubercle bacillus, because this is, it seems to me, a view which is not unlikely to concentrate our efforts too much upon one side of the problem. Above all, let us be cautious lest in concentrating our attention too exclusively on the bacillus we may divert the tide of energy and financial support from the continuance of those indirect measures which have apparently done so much not only for the reduction of pulmonary tuberculosis but also for the abatement of multiple other conditions detrimental to health and well-being.

\section{A CASE OF RECURRENT VARIOLOID RASH FOLLOWING VACCINATION.}

By R. W. C. PIERCE, B.So., M.B. LoND., D.P.H. CAMB., MEDICAL OFFICER TO THE GULDFORD, GODALMING, AND WOKING JOINT HOSPITAI BOARD.

A BoY, aged 15 years, whose primary vaccination took place at seven years of age and was said to have been normal, was, in common with a large number of other boys attending the same school, revaccinated on Dec. 5th, 1901, with calf lymph of a well-known make. The lymph was obtained in batches of 27 or 48 tubes and each tube served for the vaccination of two boys. Nothing abnormal occurred except in the case of the boy in question who, like the others, was one of two vaccinated from the same tube. His vaccination was successful and nothing unusual was noticed about the arm. The boy left for his home in the north on Dec. 16th and was seen on the same day by his medical attendant to whom $I$ am indebted for the following history. "He came home on Dec. 16th suffering from mumps [which had been prevalent at the school] and was at once sent to bed and isolated. On Dec. $24 \mathrm{th}-$ i.e., 19 days after vaccination-small-pox showed itself, being ushered in by febrile excitement, with increase of temperature, \&c. The vesicles were numerous on the face, a fair sprinkling on the body, arms, and legs, and many on the hands and feet, including the palms and soles. The vesicles had the usual amount of areola. I do not remember if there were any in the mouth, though there were many on the lips. The eruption developed fully and followed the normal course. The general symptoms were mild. He was carefully isolated at home for six weeks. The scabs from vaccination were still on the arm when he returned home and he was steadily recovering from mumps when the small-pox showed itself."

On Feb. 22nd, 1902, the boy returned to school apparently quite well. On March 4th he was seen by the medical officer on account of conjunctival catarrh and on the 5th was placed in the school sanatorium which happened at that time to be empty. On the 6 th he developed three or four vesicles of large size about the upper lip and alæ of the nose which, in connexion with his conjunctival catarrh, were taken to be herpetic. The main part of the eruption appeared on the morning of the 7th. On that evening I saw the boy for the first time and the following are the rough notes which $I$ took then and on subsequent days :-

March 7th.-Face generally a little swollen, eyelids especially, the latter with a good deal of secretion. Lips swollen, with sordes; mouth dirty ; mucous membrane inflamed and with a few vesicles on inside of lips and on palate. Temperature normal and the patient was said to have had no rise in temperature. No pain except in masticating and swallowing. A large number of hard, small, but distinctly umbilicated shining vesicles of almost uniform size and with small areolæ covering both surfaces of the hands and wrists and many (but not so numerous) on the back, inner border, and soles of the feet. There is no tendency to grouping of the vesicles. The vesicles on the palms and soles are deeply situated beneath the hard cuticle, but slightly raising surface of latter so as to give the characteristic "shotty" feel. A few vesicles on forearms but none above elbows. Site of vaccination just discernible Several veslcles on scrotum and a few scattered over trunk and legs. One large soft bleb on upper lip and a hard

In view of the typical character and distribution of the rash (except, perhaps, that on the face) a diagnosis of modified small-pox was made. In this the medical officer to the school concurred and the diagnosis was confirmed during the next two days by two experienced medical men who were called in. The only other occupants of the sanatorium-viz. the nurse and the maid-were successfully revaccinated at once. I next saw the case on the 9th (two days later) when the condition found was as follows:-

Rash considerably changed in appearance. On palms the "shotty" feel has gone; vesicles have apparently extended laterally and content become partly absorbed; contents rather turbid in appearance. On backs of hands the pocks though still quite circular have enlargedsome considerably - to a diameter, say, of one-quarter to three-eighths of an inch; central depression marked though small. Vesicles now flatter, slightly turbid, and not so tense. Several fleshy papules over rough skin of olecranon. March 10th.-Rash on back of hand about the same as yesterday, but in a few pocks there is a small central vesicle or pustule over central dot or umbilicus, and the surrounding part of vesicle seems more " fleshy" and devoid of contents, as if contents of vesicle had exuded laterally and uniformly into the surrounding skin. No raised vesicles on palms. Lesions on feet also enlarged, red, flattened, and one or two with tiny central vesicle or pustule. March 11th.-Lips still swollen and sore. Eruption distinctly paler and now presents following appearances. Pocks with small central depression, vesicle or scab, and enlarged circular raised pinkish-red areola. Whether this is the remains of a collapsed expanded vesicle or an inflammatory areola is not evident. One or
two vesicles remain as before, only enlarged. Appearance on palms as two vesicles remain as before, only enlarged. Appearance on palms as
of circular collapsed vesicles beneath epidermis with no raising of of circular collapsed vesicles beneath epidermis with no raising of surface. March 13th - Rash still fading. Spots on dorsum of hand getting smaller and paler. A few have scabs all over spots, no more noticed with tiny crusts over umbilicus. Palms now feel harder and uneven and raised over pocks which, however, are not dark. General appearance of rash now more like usual varioloid rash at this stage. Lips still with dark crusts. Tongue unevenly furred. April 1st.feet rough from presence of unpeeled skin between sites of pocks.

In arriving at the diagnosis of varioloid the chief feature relied on at the time was the typical character and distribution of the rash. The onset was, no doubt, mild and the development of the rash was somewhat rapid even for modified small-pox, but these and other objections were outweighed by the character and distribution-viz., a vesicular, umbilicated rash, chiefly on both surfaces of the hands, wrists, and feet, with markedly "shotty" feel. Whilst the appearance of the rash on the second day of its appearance was considered typical of varioloid it must be confessed that the changes that had occurred by the fourth day were a little disconcerting - viz., the enlargement and flattening of the pocks. By the eighth day, however (March 13th), the scabs seemed to have regained the appearance of varioloid at the same stage. It may be that a larger number of vesicles ought to have been present on the face in order to conform to the typical distribution and it might be objected that one or two of these were large and bleb-like.

Obviously against the theory of its being modified smallpox was the absence of a severe onset and fever. There was certainly considerable constitutional disturbance as shown by the condition of the tongue, lips, \&c., and the presence of anorexia. The strongest evidence against is the fact that the patient had an attack of what was taken to be small-pox two months before and what is scarcely less significant - that he was successfully revaccinated three months previously. There was no known exposure to infection on either occasion. A case of small-pox of unknown origin was, however, notified in a neighbouring town on Feb. 17th and several cases occurred at the latter end of March in the town close to which the school is situated-the origin of which also was untraced. The boy was in the habit of going by train to different places with the football team and he travelled from the north through London on Feb. 22nd-i.e., 12 days before the rash appeared in the second attack. In short, the possibility of exposure to infection could not be altogether excluded.

With regard to the question whether the two attacks were of the same nature, it may be mentioned that the patient himself as well as his mother who helped to nurse him on both occasions, were satisfied as to the similarity of the attacks which had but minor differences. From the data available it is probable that the two attacks, whatever their nature, were identical. Even allowing that the attacks were dissimilar in character, one being, e.g., varioloid and one a manifestation of vaccinia, the explanation of the attacks in view of the almost equal immunity against recurrence mutually exhibited by the two infections would be none the less difficult.

The alternative diagnosis of the case is that the rash had some connexion with the revaccination. As already mentioned the lymph used was part of a large batch obtained at the same time and no abnormal results followed its use in any other case. The maker when applied to wrote that "he If 3 
had made no alteration in the methods of preparing lymph for many years past and all tubes of a batch were absolutely alike." In the recent literature, however, I have been unable to find a case on all fours with this. It differed from the recorded cases of generalised vaccinia in that there was no recrudescence at or near the site of the original vesicles and that the rash did not appear until nearly three weeks after vaccination. Dr. T. D. Acland in his exhaustive article on vaccinia in Allbutt's "System of Medicine" states that "vaccinal eruptions are usually characterised by their temporary duration and irregular distribution and by their concurrence with vaccination; they were often attended with much irritation, considerable general disturbance, and some pyrexia." "Generalised vaccinia occurs, as a rule, comparatively early after vaccination, either one or two days before or one or two days after the pock at the seat of inoculation has arrived at maturity-that is to say, not generally before the fourth day or after the tenth. The date of its appearance may, however, vary considerably."

During the recent epidemic of small-pox many cases of vaccinal eruption have been recorded. Dr. Norman Walker ${ }^{1}$ in 1901 published and illustrated a case of erythema multiforme closely resembling small-pox which was somewhat similar to the case under notice. It was not at first recognised as having any connexion with vaccination, but four similar cases were subsequently seen in which "the erythema appeared in from four to five weeks after the vaccination and in all cases there was a recrudescence of activity in the vaccination marks. In the first of these cases the lesions were so like those of small-pox that the patient was very nearly removed to hospital."

Bowen, ${ }^{2}$ in September, 1901, published an article on six casses of Bullous Dermatitis following Vaccination and resembling Dermatitis Herpetiformis which were observed in Boston from 1895 to 1900. These appear to have been cases of mixed bullous and vesicular eruption of various sizes and with marked grouping, the eruption appearing from one to four weeks after vaccination and persisting with occasional intervals of freedom for months or years. Itching was usually absent. There was a tendency to grouping about the mouth, nose, ears, the backs of the hands and wrists, the ankles, and the feet.

A case of general vaccinia was published ${ }^{3}$ last year by Freeman in which several "shotty" papules occurred about the left wrist and back of the hand on the sixth day after vaccination. On the eighth day all the papules were either vesicular or semi-pustular and were umbilicated and multilocular. The palms were quite free as were all other parts of the body except those mentioned. Another case was described ${ }^{4}$ by Stewart in which three weeks after revaccination a man developed numerous large " shotty" papules on the left side of his neck which next day covered the entire neck. There were many vesicles which showed well-marked umbilication. The wrists and forearms, the back of the hands, and forehead then became covered with a profuse papular rash. All trace of the eruption had disappeared in about a week and was succeeded by a slight brawny desquamation lasting a few days.

Numerous cases of recrudescence of the vaccine vesicles within a few weeks of vaccination have been published and a few cases of "latent" vaccinia in which vesicles or scabs formed on the sites of the original and unsuccessful vaccination in one instance two and a half years later, as published by the late Dr. J. W. Washbourn, ${ }^{5}$ and in another nine months later, reported by Dr. J. Mackenzie. ${ }^{6}$ of the recently published cases to which I have been able to refer, the one now under notice appears to have more closely resembled Dr. Norman Walker's case than any other. In the latter, however, the lesions, as shown by the illustration published, seem to have been of various sizes and the umbilication not very well marked. Moreover, the eruption is reported to have rapidly disappeared and there is no history of "peeling." In none of the other cases does there appear to have been a well-marked eruption on the palms with the characteristic "shotty" feel.

The nature of the attacks and the explanation of the recurrence I must leave to those more competent to form an

1 Scottish Medical and Surgical Journal, April, 1901.

1901

2 Journal of Cutaneous and Genito-Urinary Diseases, September, p. 509 . opinion. It was, however, felt at the time of the second attack, in view of its very suspicious character and similarity to the previous attack, which had passed as smallpox without question, that the isolation of the patient was the most prudent course to pursue.

The case may have an interesting bearing on the connexion between variola and vaccinia and, assuming that the eruption was caused by the vaccination, suggests that vaccinia when introduced into a subject of bigh susceptibility or of a certain idiosyncrasy may partly revert to its original character. It is an interesting fact that the boy's mother when revaccinated developed a fresh vesicle on the site of the successful vaccination seven weeks later, which suggests an unusual family "receptivity."

As the possibility of exposure to the infection of smallpox can, however, not be excluded that disease must be considered, and although a severe onset with fever is usually deemed essential to the diagnosis of the disease it might be urged that the recent vaccination, whilst not sufficiently protective against an attack of small-pox, was yet powerful enough greatly to modify the symptoms. Guildford.

\section{THE ILL-HEALTH OF RICHARD WAGNER.}

\section{BY GEORGE M. GOULD, A.M., M.D.,} EDITOR OF " AMERICAN MEDIOINE."

THE following quotations are from the Life of Richard Wagner by Glasenapp and Ellis, and from the volumes of Letters to Heckel, Wesendonck, and Liszt. I regret exceedingly that the reproduction here of so large a number of excerpts is necessary. I have omitted many that it seemed possible to spare and not to spoil the clinical picture. Only by careful reading can one get a clear idea of Wagner's sufferings and symptoms and be thus enabled to come to a sound diagnosis of the one malady that resulted in such various and lifelong symptoms.

Richard Wagner was born in 1813...... His delicate constitution required peculiar care, for he was already troubled with that irritating required peculiar care, for he was already troubled with that irritating form of erysipelas (? erythema or eczema) which recurred at intervals
throughout life...... Down to his sixth year he had no regular throughout life...... Down to his sixth year he had no regular lessons ; his mother wished to give him time to pick up strength and
would not have him plagued with school work. ...... A pale, slim little would not have him plagued with school work. ....... A pale, slim little
chap in short-armed frocks, but unruly enough already-thus these chap in short-armed frocks, but unruly eno

My good uncle tried his best to put me through some educational training. ...... That I did not profit much by his instruction was, I fear my own fault. I preferred rambling about the little country town and its environs, to learning the rules of grammar...... I often beguiled my uncle into reading me a story that I might avoid working. (1821 or 1822.)

By night they had to suffer for each other, as both were most excitable and fitful sleepers....... Cäcilie had plenty to say of her brother's sudden shouts and talking in his sleep, his laughter and tears in the night. (1822-23.)

To roam about the country was his chief delight. (Ditto.)

He ranked among the best pupils in that gymnasium from the first and passed through various divisions and classes with fair rapidity. (1822-27.)

He was plagued with his cutaneous malady even in his school days. .... Repeated attacks of the kind. ...... An attack would be preceded by depression of spirits and irritability of temper. Conscious of his growing peevishness he would seek refuge in solitude. As soon as the
attack was subdued his bright animal spirits returned. (Ditto.)

The refinement and energy of his features and the look of wanness and suffering they wore. (About 1838.)

The prose must be turned into verse and the music composed in a fortnight. ..... His nerves have been so overtaxed that he has "often fortnight. ..... His nerves have been so overtaxed that he has "

sat down and wept for a quarter of an hour at a stretch." (1843.)
Constant victimage to a feeble stomach while instrumenting Tanhouruser. (1845.)

My whole being had been so consumed with ardour for my task that the nearer I approached its completion the more I was haunted by the the nearer I approached its completion the more $I$ was haunted by the
notion that a sudden death would stay my hand, so that when at last notion that a sudden death would stay my hand, so that when at last
$I$ wrote its closing chord I felt as joyful as if I had escaped some mortal danger. (1845.)

Lonely walks. (1845.)

Devoted some five weeks from July $3 \mathrm{rd}$ to humouring his health as well as his unresting brain would let him. (1845.)

Despite the doctor's warnings against my engaging in any such occupation. (Working at Lohengrin, 1845.)

The doctor's orders were so emphatic against any interruption of his present cure that Wagner was obliged to abandon the outing. ...... The reason for declining was that a determination of blood to the brain brought on by his exertions of the past season, had not yet left him. (Ditto.)

Scarcely could he himself say for certain whether his state of health were the cause of his low spirits or they the ground of his feeling so unwell ; perhaps it was a little of both. (1846.)

The condition of his health just now is proved by his obtaining a three months' leave of absence "to breathe again as man and artist" in Saxon Switzerland. (1846.) 